\title{
RETRACTION
}

DOI: $10.3892 /$ etm.2020.9168

\section{Hospital information technology in home care (Review)}

\author{
XIAO-YING ZHANG and PEI-YING ZHANG
}

Exp Ther Med 12:2408-2410,2016;DOI: 10.3892/etm.2016.3664

Following the publication of this article, an interested reader drew to our attention that the flow of the text, and the wording of numerous passages of text within the article, bore striking and unexpected similarities to the wording employed in a $\mathrm{PhD}$ thesis by Carina Nilsson at the Luleå University of Technology in Sweden in 2012 entitled "Information and Communication Technology as a Tool for Support in Home Care".

After having conducted an internal investigation, the Editor of Experimental and Therapeutic Medicine has determined beyond all reasonable doubt that the review submitted to the Journal shared an unacceptable level of identity with the PhD thesis by Carina Nilsson. The authors were contacted about these apparent similarities between their review and the thesis, although they failed to respond to our query in this regard. The Editor of Experimental and Therapeutic Medicine deeply regrets that this article was not intercepted by our own checks for plagiarism prior to the publication of the review, and sincerely apologizes to the author of the $\mathrm{PhD}$ thesis and the readership for the inconvenience caused. We also thank the reader for bringing this matter to our attention. 